\title{
Interpretation of Serum Creatine Kinase in Suspected Myocardial Infarction
}

\author{
B. B. SCOTT, A. V. SIMMONS, K. E. NEWTON, R. B. PAYNE
}

of everyday activity may give rise to daily variation (Griffiths, 1966; Savignano et al., 1969).

The present investigation was designed to establish a normal range of serum CK for the diagnosis of myocardial infarction and to determine whether intramuscular injections of commonly used analgesics may cause significant and misleading increases of the enzyme. As a preliminary step we thought it important to determine the degree of day-to-day variation in CK levels in healthy people. investigate the normal range, the daily variation in healthy people, and the effect of intramuscular injections of pentazocine or diamorphine.

There was considerable daily variation in the healthy controls, apparently related to exercise. In defining both the normal range and the significance of day-to-day increases in the serum CK account should be taken of this factor. An upper limit of normal of $210 \mathrm{IU} / 1$. should apply to previously ambulant patients and of $165 \mathrm{IU} / 1$. to patients previously at rest. An increase greater than $85 \%$ in successive daily values is uncommon in health.

Intramuscular injections of both pentazocine and diamorphine caused a significant rise in the serum CK in six out of 25 patients. The highest rise observed was from $64 \mathrm{IU} / 1$. to $395 \mathrm{IU} / 1$. Caution is therefore urged in the diagnosis of myocardial infarction from the serum CK values when these intramuscular injections have been given.

\section{Introduction}

Creatine/adenosine triphosphate phosphotransferase (creatine kinase (CK)) activity is the most reliable single enzyme test for the diagnosis of recent myocardial infarction (Goldberg and Winfield, 1972). The serum enzyme activity increases rapidly after infarction and, contrary to early reports using assay systems not incorporating sulphydryl reagents, activity may take as long as six or seven days to return to baseline values (Dalal et al., 1972).

An increase in serum $\mathrm{CK}$ is not specific for myocardial infarction, however, since the enzyme is also found in high concentration in other muscle and in the brain and may be released after disease or damage to these tissues (Ebashi et al., 1959; Dubo et al., 1967; Savignano et al., 1969; Watkins and Lewis, 1972). Damage to muscle after intramuscular injection might, therefore, be expected to cause an increase of serum CK. This could be a source of confusion in the interpretation of $\mathrm{CK}$ values in patients with suspected myocardial infarction since many are given intramuscular injections of analgesic drugs. Nevertheless, there is very little information in the literature on the effect of such injections.

Increases in serum CK after severe exercise are well documented (Griffiths, 1966; Vejjajiva and Teasdale, 1965), and there is also evidence suggesting that differences in the amount

\footnotetext{
University Department of Medicine and Department of Chemical Pathology, St. James's Hospital, Leeds LS9 7TF

B. B. SCOTT, M.B., M.R.c.P., Research Fellow

A. V. SIMMONS, M.B., M.R.C.P., Consultant Physician

A. V. NIMWTON, B.SC., Biochemist

R. B. PAYNE, M.D., M.R.C.PATH., Consultant Chemical Pathologist
}

\section{Subjects and Methods}

Single specimens of blood were taken from 116 randomly selected willing blood donors at the end of blood donation. There were 60 men and 56 women. To determine the effect of the donation on serum CK blood samples were also taken before donation in 20 of the donors.

Serum CK activities were studied in all 167 patients, who were admitted to this hospital with suspected myocardial infarction during a six-month period, who had estimations made on three successive days and in whom the initial value was less than $300 \mathrm{IU} / 1$.

Serum CK was measured also in 20 hospital personnel on three or four consecutive days. They were asked to report any severe exercise immediately before or during the study.

Intramuscular Injections in Convalescent Patients. - Twentyfive patients who had been admitted to hospital with myocardial infarction gave their informed consent to intramuscular injections of pentazocine $(30 \mathrm{mg}$ in $2 \mathrm{ml}$ ) or diamorphine $(10 \mathrm{mg}$ in $2 \mathrm{ml}$ ) during the second week after infarction. There was no clinical suggestion of reinfarction in any patient. In most cases the drug chosen was that which had been given on admission. Fifteen patients received pentazocine and 10 diamorphine. Serum CK was measured immediately before and usually for three days after the injection.

CK Measurements. - CK activity was measured using a modification of the method of Oliver (1955). The reagents were purchased as Eskalab tablets from Smith Kline Instrument Company. The reaction was carried out at $37^{\circ} \mathrm{C}$ using an Eskalab Alpha spectrophotometer at $340 \mathrm{~nm}$. A 10-minute preincubation lag phase was allowed for the reactions to linearize before the two-point kinetic assay of activity was carried out over a five-minute incubation. For quality control of the analyses we used Eskalab Normal and Abnormal control sera. Only eight $(7 \cdot 8 \%)$ out of 102 readings fell outside the manufacturer's specifications. Means obtained in our laboratory were not significantly different from those of the manufacturer. For Eskalab normal sera the manufacturer's value (mean \pm 2 S.D.) was $66 \pm 17 \mathrm{IU} / 1$. and our observed value was $67 \pm 24 \mathrm{IU} / 1$. and for Eskalab abnormal sera the values were $550 \pm 115 \mathrm{IU} / \mathrm{l}$. and $524 \pm 134$ IU $/ 1$. respectively.

Statistical Analysis.-The cumulative frequency of the enzyme activities obtained from blood donors was plotted on both arithmetic and logarithmic probability paper. The data best fitted a logarithmic distribution. For the purpose of statistical analysis, therefore, enzyme activities were transformed to logarithms. 


\section{Results}

NORMAL RANGE FROM BLOOD DONORS

The $95 \%$ confidence limits in the 116 donors calculated from the logarithm of the enzyme values were 26-200 IU/1. The range for men was 33-220 IU/1. and for women 23-164 IU/1. There was no significant difference between serum CK levels before and after blood donation in the 20 donors studied ( $P>0 \cdot 1$ using Wilcoxon's matched-pairs signed-ranks test).

\section{SERUM CK IN PATIENTS WITH SUSPECTED MYOCARDIAL INFARCTION}

To determine whether the normal range derived from blood donors was appropriate for patients with suspected myocardial infarction we first examined the data from patients admitted with this provisional diagnosis whose $C K$ values were less than $300 \mathrm{IU} / 1$. on admission, and showed no significant change over three days $(P<0.05)$. The criterion we used was that the difference between consecutive specimens did not exceed $1.96 \sqrt{2}$ times the analytical standard deviation (Campbell and Owen, 1967). Of the 167 patients 75 (45\%) fell into this category. The $95 \%$ confidence limits of the values in these patients calculated from $\log _{10}$ of the enzyme activities were 21-167 IU/1. for the first specimen, 19-163 IU/1. for the second, and 16-154 IU/1. for the third.

We next examined the combined data from both these patients and those patients whose values had shown a fall after admission. By the second day the values from the 103 patients in this combined category had $95 \%$ confidence limits of 20-165 IU/1. The values of the first day specimens from these 103 patients had $95 \%$ confidence limits of 20-210 IU/1.

A significant rise after admission was seen in 64 patients, $38 \%$ of the total. The third daily specimen showed a higher value than the second in only two of the 64 patients, and in both these patients a highly significant rise had already been observed.

\section{NORMAI RANGE AND DAILY VARIATION IN HEALTHY ADULTS}

Three or four consecutive daily specimens taken from 20 healthy, ambulant hospital personnel showed serum CK values with 95\% confidence limits calculated from the logarithm of the enzyme activities of 31-208 IU/1. Though there was no statistically significant difference between the means of the logarithm of the enzyme activities on successive days inspection of the data suggested that values for normal individuals tended to fall during the first part of the week. Wilcoxon's matched-pairs signed-ranks test showed that Wednesday's values were significantly lower than Tuesday's for individuals $(P<0.025)$. Significant increases in enzyme activity which were observed during the week could usually be related to increased exercise.

There was a day-to-day increase in the daily value on 24 occasions. The highest rise was from $145 \mathrm{IU}$ to $220 \mathrm{IU} / 1$. The variation was assessed by calculating the standard deviation from $\log _{10}$ of the enzyme activities of pairs using the equation

$$
\text { S.D. }=\sqrt{\frac{\text { sum of (differences }}{2 \times \text { number of pairs }}}
$$

For the 24 pairs $\log _{10}$ S.D. was 0.0921. An increase in enzyme activity in a patient could therefore be said to exceed that which might occur in health at $P<0.05$ if $\log _{10}$ (day 2 value) - $\log _{10}$ (day 1 value) was greater than 2.06 $\sqrt{2} \times 0.0921$ (Campbell and Owen, 1967). Thus, from this we can calculate that an increase of at least $85 \%$ of the initial value can be regarded as significant.

\section{EFFECT OF INTRAMUSCULAR INJECTIONS}

On the basis of the above criterion there was a significant rise in the serum CK in six of the 25 patients who were given intramuscular injections. The results in these patients are shown in the diagram.

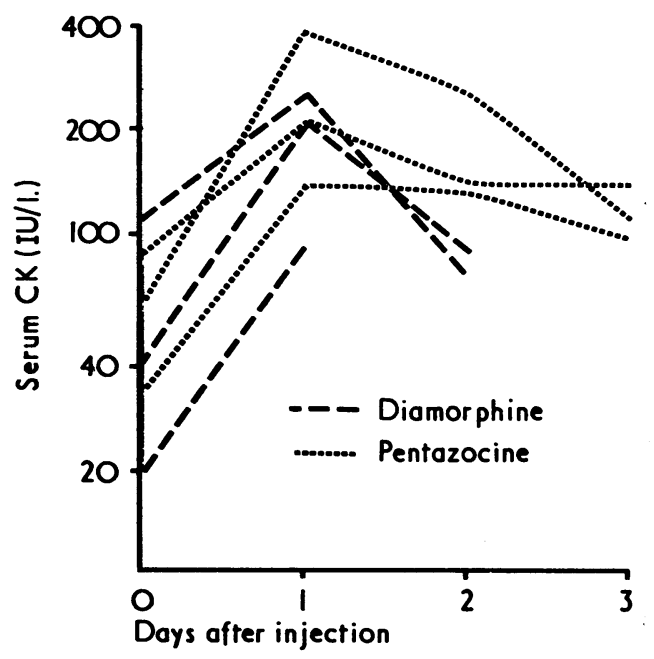

Significant rises in serum creatine kinase in six patients after intramuscular injection of diamorphine or pentazocine.

\section{Discussion}

Our first objective was to determine a normal range for the diagnosis of myocardial infarction. The normal range is derived from a control group, against which a patient's value can be judged, and should ideally be composed of individuals initially suspected of having the disease being considered but who turn out not to have it (Payne and Levell, 1968). Though this consideration is of importance for some tests-for example urinary oxogenic steroids (Levell and Payne, 1973)-for CK there was close agreement between the ranges from blood donors, healthy adults, and patients suspected of myocardial infarction who showed no significant increase in enzyme activity (see table).

Normal Ranges of Serum Creatine Kinase

\begin{tabular}{|c|c|c|c|c|}
\hline & & No. of Subjects & No. of Assays & $\underset{\text { (IU//.) }}{\operatorname{Mean} \pm 2 \text { S.D. }}$ \\
\hline $\begin{array}{l}\text { Blood donors } \\
\text { Patients } \ldots \\
\text { Staff } \quad \ldots\end{array}$ & $\begin{array}{l}\cdots \\
\cdots\end{array}$ & $\begin{array}{r}116 \\
103 \\
20\end{array}$ & $\begin{array}{r}116 \\
103 \\
74\end{array}$ & $\begin{array}{r}26-200 \\
20-210 \\
31-208\end{array}$ \\
\hline
\end{tabular}

There is well documented evidence that severe exercise such as rowing, rugby playing, or doing the London to Brighton "stroll" (Vejjajiva and Teasdale, 1965; Griffiths, 1966) can cause significant increases in serum CK. There is less information on the effect of variation in everyday activity. Griffiths (1966) found that serum CK invariably fell after 30 minutes rest in 11 subjects and that inpatients had lower values than outpatients. We have found that those patients admitted to hospital with suspected myocardial infarction who do not develop a diagnostic pattern of enzyme changes have higher serum $C K$ values on admission (upper limit $210 \mathrm{IU} / 1$.) than on the second day after resting in bed (upper limit 165 IU/1.). It seems likely that the higher initial values can be attributed to the effect of preadmission activity. It is therefore suggested that appropriate "reference ranges" for serum CK in suspected myocardial infarction are $20 \mathrm{IU}-210 \mathrm{IU} / 1$. for ambulant patients and $20 \mathrm{IU}-165 \mathrm{IU} / 1$. for those previously at rest in bed.

If changes in everyday activity affect serum $\mathrm{CK}$ values one 
would expect some day-to-day variation. Paterson and Lawrence (1972), in a study of 42 women, concluded that this was so. We too have found considerable day-to-day variation in healthy adults. The values tended to fall during the first part of the week, perhaps a consequence of the relatively sedentary nature of hospital work after the activity of the weekend. Marked increases could usually be related to increased exercise-for example, squash playing. The day-to-day variation is obviously important in assessing the significance of rises of serum CK from any cause. We have calculated that an increase should exceed $85 \%$ of the initial value to be significantly greater than variations seen in normally active adults. This criterion of significance would therefore tend to underestimate the significance of increases in patients at rest in bed.

The quality control data shows that with our manual method single estimations of enzyme activity have a coefficient of variation of $18 \%$ at $67 \mathrm{IU} / 1$. and $13 \%$ at $524 \mathrm{IU} / 1$. Thus, analytical variation makes a significant contribution to our criterion of significance. Future improved analytical methods will probably allow a smaller change in enzyme activity to be recognized as significant.

Though intramuscular injections might confuse the interpretation of serum CK (Hess et al., 1964; Cohen, 1972; Goldberg and Winfield, 1972) a review of the literature shows that very few drugs have been adequately studied. Marked increases of serum CK in six out of 14 patients after single injections of chlorpromazine have been well documented by Meltzer et al. (1970), who also showed increases in both subjects given an injection of phenobarbital. Fässler and Vorburger (1973) in a study of 24 subjects stated that "significant rises" of serum CK resulted from injection of diazepam and pentazocine, but details were not given of the magnitude or frequency of such rises. Batsakis et al. (1968) and Hess et al. (1967) found raised serum CK values in patients given frequent injections of penicillin, but no preinjection values were given. The diagnoses were not stated except in one patient who had pneumonia, a reported cause of raised CK values (Vélez-Garcia, 1966; Perkoff, 1968). Batsakis et al. (1968) also found raised values in four subjects receiving four-hourly injections of morphine, but no preinjection values were given and again the diagnoses were not stated. Chahine et al. (1974) showed that increases in serum CK after cardiac catheterization could be related to prior intramuscular injections of various drugs, but the effects of the individual drugs were not assessed.

We found that single injections of diamorphine and pentazocine cause significant increases of serum $C K$ values in about a quarter of patients (three out of 15 given pentazocine; three out of 10 given diamorphine). The greatest increase was from $64 \mathrm{IU}$ to $395 \mathrm{IU} / 1$. These two drugs are the analgesics most commonly used for myocardial infarction in this hospital and the increase in serum CK associated with their use could cause confusion in diagnosis. We suggest that when possible blood should be collected before the first injection to detect any early diagnostic increase of serum CK. Any subsequent rise must be interpreted with caution.

Despite the effects of exercise and of intramuscular injections on serum CK values, Goldberg and Winfield (1972) showed that serum $C K$ was the most reliable single enzyme test for the diagnosis of recent myocardial infarction. In the future it may be possible to measure the cardiac isoenzyme of CK routinely (Konttinen and Somer, 1973; Mercer, 1974). Meanwhile, consideration of the effects of exercise and injections along the lines we have suggested should lead to greater accuracy in diagnosis.

We thank Dr. R. B. Williams, senior registrar in pathology, for the collection of specimens from blood donors.

Requests for reprints should be addressed to K. E. Newton, Department of Chemical Pathology, St. James's Hospital, Leeds LS9 7TF.

\section{References}

Batsakis, J. G., et al. (1968). Clinical Biochemistry, 2, 125.

Campbell, D. G., and Owen, J. A. (1967). Clinical Biochemistry, 1, 3

Chahine, R. A., Eber, L. M., and Kattus, A. A. (1974). American Heart fournal, 87, 170 .

Cohen, L. (1972). Fournal of the American Medical Association, 219, 625.

Dalal, F. R., Cilley, J., jun., and Winsten, S. (1972). Clinical Chemistry, 18, 330.

Dubo, H., et al. (1967). Lancet, 2, 743.

Ebashi, S. L., et al. (1959). Fournal of Biochemistry, 46, 103

Fässler, B., and Vorburger, C. (1973). Schweizerische medizinische Wochen-

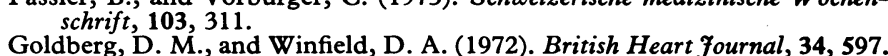

Goldberg, D. M., and Winfield, D. A. (1972). British

Griffiths, P. D. (1966). Clinica Chimica Acta, 13, 413.
Hess, J. W., et al. (1964). Annals of Internal Medicine, 61, 1015.

Hess, J. W., et al. (1967). Clinical Chemistry, 13, 994.

Konttinen, A., and Somer, H. (1973). British Medical fournal, 1, 386

Levell, M. J., and Payne, R. B. (1973). Diagnostica, No. 28, p. 10.

Meltzer, H. Y., Mrozach, S., and Boyer, M. (1970). American fournal of Medical Sciences, 259, 42 .

Mercer, D. W. (1974). Clinical Chemistry, 20, 36.

Oliver, I. T. (1955). Biochemical fournal, 61, 116

Paterson, Y., and Lawrence, E. F. (1972). Clinica Chimica Acta, 42, 131.

Payne, R. B., and Levell, M. J. (1968). Clinical Chemistry, 14, 172.

Perkoff, G. T. (1968). Archives of Internal Medicine, 122, 326.

Savignano, T., Hanok, A., and Kuo, J. (1969). American fournal of Clinical Pathology, 51, 76 .

Veijajiva, A., and Teasdale, G. M. (1965). British Medical fournal, 1, 1653.

Vejiajiva, A., and Teasdale, G. M. (1965). British Medical fournal, 1, 1653.
Vélez-Garcia, E., et al. (1966). Fournal of Laboratory and Clinical Medicine, 68, 636 .

Watkins, S. M., and Lewis, A. (1972). British Medical fournal, 3, 733.

\section{Pruritic Effect of Bile Salts}

\section{J. KIRBY， K. W. HEATON, J. L. BURTON}

British Medical fournal, 1974, 4, 693-695

\section{Summary}

The pruritic effect of purified bile salts has been tested by applying them to blister bases. All the salts tested were

\footnotetext{
University Department of Dermatology, Bristol Royal Infirmary, Bristol BS2 8HW

J. KIRBY, M.R.C.P., Registrar (Present address : Department of Dermatology, St. Bartholomew's Hospital, London)

J. L. BURTON, M.D., M.R.C.P., Consultant Dermatologist, Senior Lecturer

University Department of Medicine, Bristol Royal Infirmary, Bristol BS2 8HW

K. W. HEATON, M.D., F.R.C.P., Consultant Physician, Senior Lecturer
}

pruritogens, but the dihydroxy salts (especially unconjugated chenodeoxycholate) were more effective than the trihydroxy salts. This may explain the poor correlation between total serum bile salt concentration and pruritus in obstructive jaundice.

\section{Introduction}

The pruritus of obstructive jaundice is thought to be due to bile salt retention (Herndon, 1972). Several previous attempts to induce itching by applying bile salts to the skin have been unsuccessful, however (Brulé and Cottet, 1942; Schoenfield, 1969), and the correlation between serum bile salt concentration and pruritus is poor (Osborn et al., 1959; Datta and Sherlock, 1963; Neale et al., 1971). It seems likely that the various salts 